\title{
Comunicación
}

\section{SEROPREVALENCIA DE Brucella sp. EN CAPRINOS DE HUAROCHIRÍ, LIMA}

\author{
Wilder Rojas G. ${ }^{1}$, Alfredo Delgado C. ${ }^{2}$ y Roberto Evaristo R. ${ }^{3}$
}

\section{Abstract}

\begin{abstract}
The purpose of the present study was to determine the seroprevalence of Brucella sp. in goats from 10 districts of the Huarochirí province, Lima. Blood samples were collected from 384 female goats older than 6 months of age for the detection of antibodies against Brucella sp. using the Rose Bengal test. None of the samples resulted positive.
\end{abstract}

Key words: Brucella sp., seroprevalence, Rose Bengal, goat, Huarochirí

La explotación caprina en el Perú se encuentra muy difundida, con una población estimada de 2’047,718 animales, donde el 70\% se encuentra en el norte del país. El departamento de Lima tiene una población cercana a los 184,000 caprinos, de los cuales el $24.4 \%$ se encuentra en la provincia de Huarochirí (MINAG, 2004).

La crianza de caprinos en el Perú, actividad ganadera que aun es considerada como secundaria, se encuentra bajo la tenencia de personas de bajos recursos económicos. La crianza de estos animales es mayormente en pasturas comunales y en instalaciones simples con altos niveles de contaminación. A pesar de esto, tiene una gran repercusión económica y social en la población rural (Arroyo, 1998; Acha y Szifres, 1988).
La brucelosis es producida por una bacteria del género Brucella que afecta a todas las especies de animales domésticos y silvestres (Wrathall et al., 1993). Es una zoonosis de distribución mundial, donde Perú y México tienen una incidencia muy alta (Sanmartino, 2001).

El género Brucella comprende 7 especies: B. abortus, B. melitensis, B. suis, $B$. canis, B. ovis, B. neotomae y B. maris, siendo las cuatro primeras de importancia en salud pública. Son organismos intracelulares, obligatorios y resistentes a la fagocitosis, que viven y se multiplican en las células polimorfonucleares y en los macrófagos, distribuyéndose a los órganos linfoides donde forman granulomas con células epitelioides, linfocitos y plasmocitos que pueden llegar a caseificarse (Alton et al., 1998; Bercovich, 1988; Sanmartino, 2001).

\footnotetext{
${ }^{1}$ Práctica privada

${ }^{2}$ Clínica de Animales Mayores, FMV-UNMSM. E-mail: aldelgado@viabcp.com

${ }^{3}$ Facultad de Veterinaria y Zootecnia, Universidad Peruana Cayetano Heredia
} 
Cuadro 1. Estratificación del muestreo de sangre en caprinos de 10 distritos de la provincia de Huarochirí, Lima, para la determinación de la prevalencia de brucelosis (2004)

\begin{tabular}{lcc}
\hline Distritos & Población caprina & $\mathrm{N}^{\mathrm{o}}$ de muestras \\
\hline San Mateo & 2,500 & 64 \\
Matucana & 2,300 & 59 \\
Surco & 1,500 & 39 \\
San Bartolomé & 1,360 & 35 \\
Huarochirí & 1,800 & 46 \\
Mariatana & 1,200 & 31 \\
Tupicocha & 1,000 & 26 \\
Santo Domingo de Olleros & 1,300 & 34 \\
Langa & 1,000 & 26 \\
Antioquia & 950 & 24 \\
\hline
\end{tabular}

El germen causal tiene marcada afinidad hacia los órganos reproductivos de ovejas y cabras causando transtornos de la fertilidad, abortos, natimortos y ocasionalmente mastitis en las hembras, así como inflamaciones testiculares en los machos (Nicoletti, 1980; Sangari y Agüero, 1996; Blaha, 1995).

El humano se infecta por contacto directo o por ingestión de productos o subproductos de origen animal, donde la principal fuente de infección la constituye el queso fresco elaborado con leche cruda proveniente de cabras infectadas (Acha y Szifres, 1988). El Ministerio de Salud registró cerca de 1,400 casos anuales entre el 2000 y el 2002, ocurriendo cerca del $95 \%$ en Lima y Callao, afectando especialmente a la clase social baja y media baja (MINAG, 2004). Debido a esto, se planteó estudiar la seroprevalencia de Brucella sp. en cabras de 10 distritos de la provincia de Huarochirí, Lima, a fin de determinar el riesgo potencial de la brucelosis caprina sobre el hombre.
Huarochirí está ubicada a 2,800 msnm $y$ presenta una temperatura anual que fluctúa entre 7 a $30^{\circ} \mathrm{C}$. Es una zona de valles interandinos que tienen como barreras naturales los cerros y quebradas, no permitiendo un fácil acceso de criadores con grupos de animales de otros distritos o provincias.

Entre enero y marzo del 2004 se tomaron 384 muestras de sangre de cabras hembras no vacunadas mayores de 6 meses de edad (Cuadro 1). El suero fue separado mediante centrifugación y mantenido en refrigeración hasta su procesamiento.

Se utilizó la prueba de Rosa de Bengala para la detección de anticuerpos contra Brucella sp. La prueba se llevó a cabo en el campo, según el Manual de Normas para las Pruebas de Diagnóstico y las Vacunas de la Oficina Internacional de Epizootias (OIE, 1992), así como del VI Informe del Comité Mixto FAO/OMS de Expertos en Brucelosis (FAO/OMS, 1986). Ésta es una prueba de campo de simple realización con una especi- 
ficidad de $100 \%$ y una sensibilidad de $75 \%$ (Corbel, 1991; FAO/OMS, 1986; Tizard, 1995) y se recomienda para estudios de seroprevalencia en lugares donde no se practica la vacunación contra brucelosis.

Ninguna muestra resultó positiva a Brucella sp. Estos animales son de distritos que se encuentran en zonas de altura y alejados de otras cuencas caprinas, de allí que esa especie de barrera geográfica no haya permitido el ingreso de la brucelosis caprina a esta zona. Por otro lado, hay que tener en cuenta que desde hace cuatro años se realizan monitoreos de la enfermedad en los alrededores de Huarochirí, y se vacunan a todos los animales mayores de tres meses de edad en los distritos colindantes. Además, se concientiza al productor de la importancia del problema y se le compromete en el programa de control y erradicación de la brucelosis caprina.

Hace años se reportó en el departamento de Ancash una prevalencia de $43 \%$ de brucelosis caprina, debido principalmente al sistema de crianza transhumante de la zona (Escurra, 1970). En años recientes, en el valle del Chillón, Canta, se determinó una prevalencia de $2.8 \%$ de $B$. melitensis siendo de 4.6 y $1 \%$ en animales no vacunados y vacunados, respectivamente (Vargas, 1999). Estos últimos datos son más cercanos a los del presente estudio, debido a que en ambas zonas existen campañas de control y erradicación de brucelosis.

\section{Literatura Citada}

1. Acha, P.N.; B. Szifres. 1988. Zoonosis $y$ enfermedades transmisibles comunes al hombre y a los animales. $2^{\text {nd }}$ ed. $p$ 1434. Organización Panamericana de la Salud. Washington.

2. Alton, G.G.; L.M. Jones; R. Angus; J.M. Verger. 1998. Techniques for the brucellosis laboratory. INRA. Paris, France. 9 p.
3. Arroyo, O. 1998. Producción de caprinos. Ed. Procabra. Lima, 33 p.

4. Bercovich, Z. 1998. Maintenance of Brucella abortus free herds: A review with emphasis on the epidemiology and problems in diagnosing brucellosis in areas of low prevalence. Vet. Quart. 20: 81-88.

5. Blaha, T. 1995. Epidemiología especial veterinaria. Ed. Acribia. Zaragoza, España. 211 p.

6. Corbel, M.J. 1991. Brucelosis. En: Fertilidad e infertilidad en la práctica veterinaria. Laing, J.A.; W.J. Brinley Morgan; W.C. Wagner (eds). $4^{\text {ta }}$ ed. $p$ 201-236. Ed. Interamericana. España.

7. Escurra, E. 1970. Epidemiología de la brucellosis caprina en los departamentos de La Libertad y Ancash. Tesis de Bachillerato. Facultad de Medicina, Univ. Nacional Mayor de San Marcos. Lima. 29 p.

8. FAO/OMS. 1986. Comité Mixto de Expertos en Brucelosis. Sexto Informe. Serie de Informes Técnicos 740. OMS. Ginebra. 149 p.

9. Ministerio de Agricultura (MINAG). 2004. Boletín de Control de la Brucelosis Caprina 1999-2004. Servicio Nacional Agrario, SENASA. 8 p.

10. Nicoletti, P. 1980. The epidemiology of bovine brucellosis. Adv. Vet. Sci. Comp. Med. 24: 69-98.

11. Oficina Internacional de Epizootias (OIE). 1992. Suplemento al Manual de Normas para las Pruebas de Diagnóstico y las Vacunas para las Enfermedades de las Listas A y B de los Mamíferos, Pájaros y Abejas. $2^{\mathrm{a}}$ ed. p 85-89. OIE. París, Francia.

12. Sanmartino, L. 2001. Brucelosis en Latinoamérica: Situación actual y perspectivas de control. XXIV Reunión Científica Peruana de Producción Animal. Perú.

13. Sangari, F.J.; J. Agüero. 1996. Molecular basis of Brucella pathogenecity: an update. Microbiol. Sem. 12: 207-218. 
14. Tizard, I. 1995. Inmunología veterinaria. $4^{\mathrm{a}}$ ed. p 245-249. Ed. Interamericana. México.

15. Vargas, I. 1999. Prevalencia de $B$. melitensis en el valle de Chillón, Provincia de Canta, Departamento de Lima. Tesis de Médico Veterinario. Facultad de
Medicina Veterinaria, Univ. Nacional Mayor de San Marcos. Lima. 31 p.

16. Wrathall, A.E.; E.S. Broughton; K.P.W. Gill; G.P. Goldsmith. 1993. Serological reaction to Brucella species in British pigs. Vet. Rec. 132: 449-454. 